\title{
A PSICANÁLISE NO HOSPITAL: DOS IMPASSES ÀS CONDIÇÕES DE POSSIBILIDADES
}

Maila Do Val Machado e Daniela Sheinkman Chatelard

Maíla Do Val Machado

Especialista em

Teoria Psicanalítica

(UFMG), mestranda

em Psicologia

Clínica e Cultura

(UnB).

Daniela Sheinkman

Chatelard

Psicanalista,

professora adjunta

do Departamento

de Psicologia

Clínica do Instituto

de Psicologia

e do Programa

de Psicologia

Clínica e Cultura

(UnB), doutora

em Filosofia

(Universidade de

Paris VIII).
RESUMO: Pretende-se apresentar algumas especificidades para se identificar a clínica psicanalítica e analisar as condições de possibilidades para o trabalho analítico no hospital. Para isso, retomam-se as ideias de Ana Cristina Figueiredo referentes às condições mínimas para se caracterizar as especificidades da psicanálise. Essas questões serão articuladas, principalmente, aos artigos freudianos sobre a técnica psicanalítica. Conclui-se que é possível sustentar o trabalho analítico no hospital, mas isso depende da implicação do psicanalista nas especificidades dessa clínica e na exigência de um rigor ético de formalização de sua prática.

Palavras-chave: Psicanálise, hospital, difusão da psicanálise, formação do analista, práxis analítica.

ABSTRACT: The psychoanalysis in hospitals: from impasses to the conditions of possibilities. This paper has as main purpose to present some specificities in identifying the psychoanalytic clinic and analyzes the conditions of possibilities for the analytical work at the hospital. For that, it is recovered the ideas of Ana Cristina Figueiredo about the minimal requirements to characterize the specificities of the psychoanalytic clinic. These ideas are articulated, mainly, to the Freudian papers about the psychoanalytic technique. In conclusion, it is possible to sustain the analytical work at the hospital, but it depends on the psychoanalyst's involvement in the specificities of this clinic and in the requirement of an ethical rigor of its practice formalization.

Keywords: Psychoanalysis, hospital, diffusion of the Psychoanalysis, formation of the analyst, analytical practice. 
C ada vez mais presenciamos a difusão da psicanálise nos diversos campos do saber, o que exige do analista formalizar teoricamente a prática a partir dos próprios fundamentos do campo psicanalítico. Reinventar a psicanálise para além dos consultórios particulares é uma demanda imposta pela cultura, e, por isso, é necessário e vital o esforço do analista em recriar a psicanálise para o avanço dessa clínica.

Freud afirma seu desejo pela extensão da psicanálise em vários momentos de sua obra. No entanto, não chega a teorizar sobre a inserção da mesma nos diferentes estabelecimentos do saber. Ao tratar do futuro da psicanálise, Freud (1919 [1918a]/1996) apenas diz que os princípios psicanalíticos deveriam ser mantidos independentemente dos novos rumos que a psicanálise enfrentasse.

Seguindo essas perspectivas, tem-se que a difusão da psicanálise para além do espaço privado do consultório nos remete a uma preocupação em relação à formação do analista e à formalização da práxis analítica. Isso porque essa extensão pode fazer com que os princípios psicanalíticos corram constantemente o risco de perder seu rigor ético e específico. De fato, se essas exigências são perdidas, a psicanálise deixa de ser eficaz.

Diante dessas preocupações e dificuldades decorrentes da difusão da psicanálise, a extensão da clínica psicanalítica para os hospitais nos possibilita debater questões que colocam a práxis do psicanalista diante dos desafios clínicos, teóricos e institucionais. Dessa forma, pretende-se apresentar aqui, por meio de uma articulação entre a teoria, a prática e a pesquisa, algumas especificidades para se identificar a clínica psicanalítica e analisar as condições de possibilidades para o trabalho analítico no hospital.

\section{A DIFUSÃO DA PSICANÁLISE: PERSPECTIVAS FREUDIANAS}

Segundo Mezan (1998), Freud inicia seu projeto psicanalítico como um médico interessado nas chamadas “doenças nervosas”. As pessoas com essas doenças apresentavam alguns sintomas e comportamentos que eram inexplicáveis pela medicina. Os médicos não compreendiam os motivos pelos quais essas pessoas podiam ter uma perna paralisada ou pudessem ficar cegos de repente, sem uma lesão visível.

No começo do seu trajeto, Freud se dedica a investigar por que aqueles sintomas e comportamentos incompreensíveis podiam ocorrer, iniciando, assim, a tentativa de compreender o funcionamento da psique humana. Nesse processo, acaba criando um método para tratar esses pacientes — "inventa a psicanálise, tendo a ideia originalíssima de deixar as pessoas falarem a respeito do que lhes acontecia e buscando nessa fala elementos que pudessem dar uma pista sobre a origem, o motivo e o sentido desses sintomas" (MEZAN, 1998, p.212). Desta 
forma, Freud propõe-se a construir uma teoria capaz de explicar a origem desses sintomas e comportamentos estranhos, assim como a eficácia do método que ele planejara.

Freud inventa também a situação analítica, possibilitando aí um espaço de fala para as histéricas acusadas de serem mentirosas e fingidoras. Ele dá grande importância ao que elas dizem, mesmo quando as falas pareciam absurdas e contraditórias. Assim, "Freud se dá conta de que as pessoas, ao falarem, dizem muito mais do que imaginam estar dizendo. Cria então o primeiro conceitochave da psicanálise: o conceito de inconsciente" (idem, p.213).

De forma sucinta e de acordo com Mezan (1998), num primeiro momento, pode-se dizer que o inconsciente é aquilo de que não se tem consciência. Ao longo das suas investigações, Freud acaba percebendo que o inconsciente obedece a certa lógica e que os sintomas esquisitos dos quais as pessoas se queixam têm um sentido, desconhecido pelo próprio indivíduo. Pode-se entrever aí que Freud tem grande preocupação com as consequências lógicas das noções que vai construindo para dar conta dos fenômenos aparentemente estranhos e sem sentido com os quais se depara.

Ao lado e integrado à construção da teoria psicanalítica, ele declara o desejo de reconhecimento da psicanálise e a esperança de que, um dia, ela venha a se difundir nos diversos campos do saber. Assim, ao longo da obra freudiana, podemos recorrer a alguns textos que apresentam essa perspectiva, tais como: "Linhas de progresso na terapia psicanalítica" (1919 [1918a]/1996), "Sobre o ensino da psicanálise nas universidades" (1919 [1918b]/1996), "Psicanálise” (1926 [1925]/1996), "Explicações, aplicações e orientações" (1933 [1932]/1996).

Em “Linhas de progresso na terapia psicanalítica”, Freud (1919 [1918a]/1996), no momento em que o mundo se encontrava devastado pelos efeitos da Primeira Guerra Mundial, preocupa-se em abrir os caminhos para a psicanálise. Àquela época, ele diz que, futuramente, seriam criadas instituições que designariam psicanalistas para tratar uma considerável massa da população. Para isso, seria necessário o trabalho do analista em adaptar as técnicas às novas condições, mas enfatiza que os princípios psicanalíticos deveriam ser mantidos.

No texto "Sobre o ensino da psicanálise nas universidades" (1919 [1918b]/1996), ao tratar sobre esse tema, diz que nas investigações mentais e nas funções do intelecto, a psicanálise segue seu próprio método específico. Dessa forma, afirma que a aplicação desse método não se restringe ao campo dos distúrbios psicológicos, mas amplia-se à solução dos problemas ligados à arte, à filosofia e à religião. Além disso, ele também afirma que a psicanálise já produziu esclarecimentos sobre "a história da literatura, a mitologia, a história das civilizações e a filosofia da religião" (FREUD, 1996, p.188). No texto "Psicanálise”, Freud (1926/1996) volta a afirmar a extensão da psicanálise aos diversos 
campos do saber: "Nem houve espaço para aludir às aplicações da psicanálise (...) a outros setores do conhecimento (como a antropologia social, o estudo da religião, a história literária e a educação), onde sua influência vem constantemente aumentando" (FREUD, 1996, p.258).

Em “Explicações, aplicações e orientações”, Freud (1933 [1932]/1996), ao discutir sobre as aplicações da psicanálise às ciências naturais, diz: “Devo mencioná-lo porque é da maior importância, é tão pleno de esperanças para o futuro, talvez seja a mais importante de todas as atividades da análise. Estou pensando nas aplicações da psicanálise à educação, à criação da nova geração” (FREUD, 1996, p.145).

Atualmente, percebe-se que o futuro vislumbrado por Freud já é o nosso presente, uma vez que os psicanalistas são convocados a intervir nos diferentes campos, e a psicanálise se torna cada vez mais objeto de curiosidade de profissionais não analistas. Hoje, vê-se que muitos se interessam pelo que a psicanálise pode fornecer tanto em relação à análise quanto em termos de leitura do cotidiano e do mundo.

Entretanto, observa-se que a crescente difusão da psicanálise é acompanhada por uma preocupação sobre a formalização da práxis analítica, assim como da formação dos analistas. A extensão da psicanálise aos mais diversos meios jurídicos, educacionais, hospitalares e artísticos faz com que os dispositivos analíticos corram constantemente o risco de perderem seu rigor ético e singular.

No texto "Linhas de progresso na terapia psicanalítica", conforme citado, Freud (1919 [1918a]/1996) já localiza as novas condições que a clínica deveria enfrentar. Tratava-se de “adaptar a técnica às novas condições” (p.181) e a situação que abordava como pertencente ao futuro requeria preparação dos analistas. Ele diz: "qualquer que seja a forma que essa psicoterapia para o povo possa assumir, (...) os seus ingredientes mais efetivos e mais importantes continuarão a ser, certamente, aqueles tomados à psicanálise estrita e não tendenciosa” (FREUD, 1996, p.181). Portanto, a ideia aí inserida é a importância dos psicanalistas em abrir novos espaços para a clínica psicanalítica, uma vez que os princípios deveriam ser mantidos.

No caso dos hospitais gerais, espaço privilegiado por este trabalho, observase que a inserção da psicanálise nos coloca diante de todas essas preocupações, tornando-as desafiadoras para as condições de possibilidades da psicanálise nesses locais. A partir da prática nos hospitais, observa-se que a extensão da psicanálise para esses espaços pode fazer com que ela se misture com a promoção de tratamentos que visariam simplesmente restabelecer o equilíbrio, o bem-estar, a saúde perdida. Nesses locais, tal diluição pode ter proporcionalidade ainda maior se levarmos em consideração o próprio contexto hospitalar com todas as suas tentativas de restaurar a saúde perdida e também os motivos pelos quais 
os psicanalistas são chamados a se inserir nesses espaços. Quais seriam esses motivos e como podem se tornar preocupantes no que tange à legitimidade da psicanálise?

O psicanalista pode ser solicitado pelo médico para eliminar um fenômeno psíquico, para tentar acalmar qualquer situação de angústia ou para convencer os pacientes a aceitarem algum procedimento ao qual ele se opõe ou resiste. Eliminar, acalmar, convencer... Esses são termos que frequentemente envolvem o pedido do médico ao analista.

Muitas vezes, alguns psicanalistas, preocupados com sua aceitação, reconhecimento e eficácia imediata, se deixam corromper pelas solicitações dos médicos para eliminar, convencer e acalmar as “causas psíquicas” que estão emergindo no tratamento do paciente. Moretto (2001) afirma que o psicanalista, ao aceitar essas solicitações dos médicos, tais como foram formuladas, rompe com o próprio discurso psicanalítico e com a proposta freudiana.

O psicanalista, referenciado pela ética do desejo, não está autorizado a ordenar o que é melhor para o sujeito, a partir da posição do sujeito que sabe. De fato, a psicanálise se distancia dos tratamentos conduzidos pelos poderes das palavras ou de vários outros voltados para os medicamentos. A clínica psicanalítica não pretende ajustar o paciente a um padrão de normalidade que exclui as particularidades do sujeito.

Freud (1913/1996) afirma que a regra fundamental da psicanálise é a associação livre, ponto que marca o início do tratamento analítico. Segundo as ideias freudianas, essa regra não está do lado do analista, mas sim do paciente. Do lado do analista, fora o preceito da atenção flutuante, não há regras, mas a ética da psicanálise que é a ética do desejo. Como tal, não é uma ética do bem nem propõe nenhuma forma de universalização moral, sendo antes de tudo uma ética do bem-dizer que visa a fazer emergir o desejo de cada sujeito na sua particularidade.

A ética da psicanálise propõe ao analista acolher, mas nunca responder à demanda que lhe é dirigida pelo paciente. Dessa forma, o analista deve acolher as demandas do paciente sem, no entanto, satisfazê-las. O analista, no encontro com o paciente, vai operar com a transferência e, por meio da interpretação, coloca-se em uma posição em que o sujeito é levado a produzir, por suas próprias palavras, o saber do inconsciente.

Portanto, o trabalho do psicanalista visa a sustentar um lugar de endereçamento das questões do sujeito, sendo que o que se lhe oferece é um lugar vazio como causa de desejo. Sua função consiste em marcar o que o sujeito produz a partir da transferência para que o desejo, veiculado pela palavra, possa se revelar.

No entanto, não ceder aos pedidos médicos, tais como são formulados, assim como sustentar o seu discurso num local em que todos os procedimentos 
estão previamente determinados pelos protocolos e que ainda impõe critérios de eficácias — definidas por uma resolutividade quantificável — são grandes desafios para o psicanalista no hospital. Dessa forma, a questão que se apresenta ao analista pode ser assim formulada: de que maneira seria possível sustentar sua prática num lugar marcado pelo sofrimento físico e pela busca da saúde perdida, se seu discurso não consiste em consolar nem em curar o sujeito? O trabalho analítico no hospital exige do psicanalista colocar à prova a ética da psicanálise e as especificidades de sua clínica.

\section{AS CONDIÇÕES MÍNIMAS PARA SE CARACTERIZAR AS ESPECIFICIDADES DA CLÍNICA PSICANALÍTICA}

Neste momento, é importante mencionar uma questão que decerto norteou as discussões abordadas até aqui. Ao se introduzir a ideia de que as condições de possibilidades para sustentar a psicanálise nos hospitais dependem fundamentalmente da formação do analista e da formalização da práxis analítica, deve-se questionar: quais seriam as condições mínimas — termo utilizado por Figueiredo (1997) — para se caracterizar as especificidades da clínica psicanalítica? Como identificar a clínica psicanalítica num determinado tipo de trabalho?

É importante destacar que a obra de Figueiredo (1997) é desenvolvida a partir da experiência analítica nos ambulatórios públicos. De fato, o trabalho nesses espaços abrange diferenças em relação aos hospitais gerais. No entanto, quando Figueiredo analisa as condições mínimas, ela trata das especificidades da psicanálise e não do que é específico para o atendimento nos ambulatórios. Ela busca reafirmar a ortodoxia da psicanálise, de modo preciso e singular. Trata-se de identificar o que Freud (1919 [1918a]/1996) designou como "psicanálise estrita e não tendenciosa” (p.181), para que seja possível praticá-la com todas as suas consequências. Dessa forma, torna-se viável utilizarmos as ideias da autora neste artigo, pois, nesse momento, o objetivo é delimitar o que é específico da clínica psicanalítica. Traçar esses aspectos nos dará subsídios para analisarmos, num segundo momento, as particularidades do trabalho analítico nos hospitais gerais.

Inicialmente recorreremos ao que Figueiredo (1997) designou como condições mínimas para que se reconheça como psicanálise um modo específico de trabalho clínico. Tentaremos articular suas ideias com algumas concepções freudianas no que concerne às condições para identificarmos um trabalho analítico. Essas concepções se encontram, principalmente, nos artigos sobre a técnica psicanalítica. Longe de pretender a exaustão do tema, é importante salientar que o objetivo aqui é apenas localizar as condições mínimas para um trabalho psicanalítico de acordo com essa autora. Trata-se ainda de conferir, na 
experiência analítica, o quanto essas condições são determinadas pelos próprios fundamentos da psicanálise.

A primeira condição à qual Figueiredo (1997) faz referência é o que Freud denominou de realidade psíquica. Essa realidade é uma forma de existência do sujeito que se distingue da realidade material, uma vez que é dominada pelo império da fantasia e do desejo. De acordo com Roudinesco (1998), historicamente, a ideia de realidade psíquica nasceu do abandono da teoria da sedução e da elaboração de uma concepção do aparelho psíquico baseada no primado do inconsciente.

Em “A interpretação dos sonhos”, Freud (1900/1996) afirma que "o inconsciente é a verdadeira realidade psíquica” (FREUD, 1996, p.637) e completa: “em sua natureza mais íntima, ele nos é tão desconhecido quanto a realidade do mundo externo, e é tão incompletamente apresentado pelos dados da consciência quanto o é o mundo externo pelas comunicações de nossos órgãos sensoriais” (FREUD, 1996, p.637, grifo do autor). Em uma passagem do texto “Os caminhos da formação dos sintomas”, Freud (1917/1996), ao tratar sobre a fantasia e a realidade, expõe que "as fantasias possuem realidade psíquica, em contraste com a realidade material, e gradualmente aprendemos a entender que, no mundo das neuroses, a realidade psíquica é a realidade decisiva” (FREUD, 1996, p.370, grifo do autor). De acordo com essas ideias, Figueiredo (1997), ao abordar a realidade psíquica como uma das condições mínimas para o trabalho psicanalítico, diz: “Trata-se da única realidade que diz respeito e interessa ao sujeito, a partir da qual ele se vê, pensa, fala, sofre, trabalha; enfim, se põe no mundo e, até mesmo, se desconhece" (FIGUEIREDO, 1997, p.124).

Segundo a autora, a especificidade do trabalho psicanalítico está em ater-se às produções da fala do sujeito como indicações da realidade psíquica. Afirma ainda que "o pacto analítico é um pacto da fala. A psicanálise é uma clínica da fala. Fazer falar é uma condição da escuta e é pela escuta que a fala se constitui" (FIGUEIREDO, 1997, p.124). Aqui se explicita a regra fundamental da psicanálise para fazer trabalhar a realidade psíquica: “diga o que lhe vier à cabeça”. Conforme Freud (1913/1996) expõe, essa regra é a associação livre, método de acesso à produção do inconsciente e que marca o início do processo analítico. Segundo as concepções freudianas, a associação livre está do lado do paciente. Em relação ao analista, Freud propõe que ele não fale mais do que o indispensável para fazer com que o paciente relance seu discurso.

Nesse ponto, recorre-se a outra recomendação freudiana que envolve essa primeira condição para um tratamento psicanalítico. Freud (1912a/1996) diz: “Agora acrescentarei algumas outras regras, que servirão como uma transição da atitude do médico para o tratamento do paciente” (FREUD, 1996, p.131). Freud afirma que as técnicas que envolvem o tratamento por sugestão implicam um afastamento dos princípios psicanalíticos. Isso porque as influências sugestivas 
não revelam o que é inconsciente ao paciente. Portanto, "o médico deve ser opaco aos seus pacientes e, como um espelho, não mostrar-lhes nada, exceto o que lhe é mostrado" (FREUD, 1996, p.131).

A segunda condição mencionada por Figueiredo (1997) consiste na produção de um modo de fala através da transferência. Ela diz que a transferência é o movimento do sujeito que apresenta ao analista algo de sua realidade através da fala. O que se evidencia aí é a ideia freudiana de que a palavra é a ferramenta de trabalho da psicanálise, uma vez que essa fala é dirigida ao analista e circula num contexto transferencial.

Seguindo as perspectivas freudianas, pode-se afirmar que a clínica psicanalítica se faz sob transferência. O trabalho do analista consiste no manejo da transferência, o que exige conhecimento sobre o funcionamento do que Freud chamou de inconsciente. É a partir da transferência que o analista é colocado no psiquismo do paciente, e ele precisa fazer bom uso disso, pois é nesse lugar que o analista vai operar. Assim, a transferência pode ser definida como um processo do tratamento psicanalítico mediante o qual os desejos inconscientes do analisando referentes a objetos externos passam a se repetir, no âmbito da relação analítica, na pessoa do analista, colocado na posição desses diversos objetos. Assim, o sujeito, como dizia Freud, atualiza na transferência os seus conflitos neuróticos.

Para que possamos avançar nesta discussão sobre a transferência, recorreremos ao conceito lacaniano de "sujeito suposto saber". No texto "Proposição de 9 de outubro de 1967 sobre o psicanalista da Escola”, Lacan (1967/2003) afirma que no começo da psicanálise está a transferência. Diz ainda que o conceito de “sujeito suposto saber” é o pivô a partir do qual se articula tudo o que se refere à transferência. A resolução de se buscar um analista está vinculada à hipótese de que há um saber em jogo no sintoma ou naquilo de que a pessoa quer se desvencilhar. Dessa forma, a transferência consiste no reconhecimento do sujeito de um saber que possui, mas que lhe escapa - que saber é esse que me escapa e que, no entanto, me determina? Isso que o sujeito não sabe sobre si vai ser suposto saber ao analista. Este, ao ocupar este lugar, é suposto não como aquele que sabe, mas sim como aquele que deve receber a fala do sujeito como produção de saber. Assim, cabe ao analista, através da transferência, sustentar o lugar de endereçamento das questões do sujeito.

A terceira condição que Figueiredo (1997) expõe seria determinada concepção do tempo que é a mola-mestra da interpretação, ou seja, "uma palavra ou ação do analista só tem valor de interpretação, como efeito, num tempo posterior" (FIGUEIREDO, 1997, p.125). A concepção de tempo está presente na própria causação psíquica, indicando que o tempo para a psicanálise não é evolutivo nem linear. Isso porque, conforme Freud (1915/1996) esclarece, o inconsciente 
é atemporal, ou seja, "não são ordenados temporalmente, não se alteram com a passagem do tempo; não têm absolutamente qualquer referência ao tempo" (FREUD, 1996, p.192).

Seguindo as perspectivas freudianas, Figueiredo (1997) afirma que a concepção de tempo não se refere exatamente à ação do passado sobre o presente. Ao invés disso, de acordo com Freud, essa concepção corresponde ao esquema da constituição do trauma. Ao tratar sobre a etiologia dos sintomas neuróticos e sobre a noção de trauma, Freud (1896/1996) diz que uma criança pode sofrer uma experiência sexual de efeito traumático. Essa experiência se caracteriza pelo caráter prematuro de uma vivência a ela imposta por um adulto sedutor ou por uma criança mais velha (que já tinha sido seduzida). Esta seria a teoria da sedução, segundo a qual a neurose teria como origem um abuso sexual real: de um lado o adulto sedutor e, de outro, a criança numa situação de "passividade sexual durante o período pré-sexual” (FREUD, 1996, p.164, grifo do autor). Ressalta-se que essa experiência não é, em si, traumática, pois, em função da imaturidade sexual da criança, a experiência não provoca excitação ou elaboração psíquica por parte dela. No entanto, quando uma cena atual desperta os traços mnêmicos traumáticos da infância, há uma lembrança dessa experiência. E o momento traumático se caracteriza por essa lembrança da experiência infantil, ou seja, é o momento em que o indivíduo, após a maturidade sexual, é capaz de dar uma significação a tal experiência.

Assim sendo, a concepção de tempo para a psicanálise é a de uma retroação, ou seja, um primeiro acontecimento só tem seu sentido revelado num tempo posterior, por ocasião de um segundo acontecimento. Em acordo com as ideias freudianas, Figueiredo (1997) diz: “Temos a retroação de um tempo atual sobre o anterior, seja no trauma, na constituição da fantasia, no sintoma ou na cena analítica. É sobre os efeitos de nossos atos e falas, e também dos atos e falas dos sujeitos que podemos trabalhar" (FIGUEIREDO, 1997, p.126).

Tem-se aí a ideia de posterioridade em Freud que, em última análise, resume o conjunto da concepção freudiana da temporalidade. Essa ideia nos possibilita observar que as elaborações do sujeito ao longo do percurso analítico também se dão num tempo de posterioridade às sessões. A elaboração é um processo, uma exigência de trabalho que o sujeito se impõe "através” da análise, da presença do analista que o faz trabalhar. O analista só tem indícios desse trabalho do sujeito num tempo posterior, a partir das palavras e ações do sujeito. Esse acesso à elaboração ocorre de modo fragmentário e sempre incompleto.

A elaboração ocorre a partir das intervenções do analista e das próprias associações do sujeito. Freud (1914/1996) já afirmava que a elaboração é tarefa do paciente, "tarefa árdua para o sujeito e uma prova de paciência para o analista" (p.171). Isso porque, em relação à elaboração, “o médico nada mais tem a fazer 
senão esperar e deixar as coisas seguirem seu curso, que não pode ser evitado nem continuamente apressado” (FREUD, 1996, p.171). A partir dessas ideias, recorre-se a Lacan quando este diz que o analista é o depositário das elaborações e associações que o paciente faz fora da sessão.

Diante desse contexto, Figueiredo (1997) aponta uma questão que é fundamental nessa terceira condição para um trabalho psicanalítico. Tendo como base o processo de elaboração do sujeito em análise, a autora questiona: qual é o teor da incidência do analista nesse processo? Ela responde: "Chegamos à interpretação, onde o analista é supostamente livre para dizer o que quiser. Essa é sua tática1" (FIGUEIREDO, 1997, p.150).

Segundo Figueiredo (1997), o analisante pode receber as interpretações do analista com surpresa ou familiaridade, perplexidade ou incompreensão. Pode reconhecer algo que lhe diz respeito. Ao ouvir as palavras do analista, o analisando entende o que pode, pois não há uma correspondência unívoca entre o que o analista diz e o que o paciente interpreta. Daí a importância do analista em manejar suas palavras na análise, pois, estabelecida a transferência, essas falas podem ter efeito de interpretação. De acordo com Figueiredo (1997), “a interpretação trilha um sentido que se desdobra e se limita em determinado arranjo de significantes produzidos pelo sujeito que tecem e retecem a realidade psíquica marcando os caminhos do desejo" (FIGUEIREDO, 1997, p.153).

Nesse contexto, o que importa, então, mais do que o dito, é o efeito que a intervenção do analista produz no analisando. Há um tempo para essa incidência operar no circuito da elaboração do analisando a fim de produzir uma resposta na via da transferência. Freud (1913/1996) diz que se a intervenção do analista incidir precocemente sobre algo que o sujeito ainda não pôde dizer, o efeito é a resistência. Freud (1925 [1924]/1996) afirma que “(...) a descoberta da resistência, contudo, constitui o primeiro passo no sentido de superá-la. Assim, o trabalho de análise implica uma arte de interpretação, cujo manuseio bem-sucedido pode exigir tato e prática, mas que não é difícil de adquirir” (FREUD, 1996, p.46, grifo do autor).

A essa terceira concepção, Figueiredo (1997) articula ainda com a noção de cura. Após mencionar que essa é uma questão controvertida da psicanálise, a autora introduz a pergunta: "De que o sujeito se cura afinal? (...) Talvez se possa transformar essa pergunta em outra: do que o sujeito padece?” (FIGUEIREDO,

\footnotetext{
${ }^{1}$ Nesse ponto, a autora faz referência ao texto lacaniano "A direção do tratamento e os princípios do seu poder" (1958). Lacan desenvolve uma versão da clínica inspirada na teoria do general prussiano Karl Clausewitz sobre a guerra como cálculo cujos elementos são: a tática, a estratégia e a política. O analista se vale desses três elementos na clínica psicanalítica. Sua tática, onde é mais livre, é a interpretação; sua estratégia, onde é menos livre, é a transferência; finalmente, sua política, que domina a estratégia e tática e onde é menos livre ainda, é menos seu ser do que sua "falta-a-ser".
} 
1997, p.161). De forma sucinta, ela responde: “Se respondemos que 'ele padece dos acontecimentos da vida com uma intensidade incapacitante', concluímos que 'capacitá-lo para enfrentar a vida' já seria satisfatório. E esta não deixa de ser uma solução prática considerada tanto por Freud quanto por Lacan” (ibidem).

Freud (1912a/1996) já havia alertado os psicanalistas quanto às suas ambições terapêuticas de alcançar a cura. Conforme exposto antes, a psicanálise não visa a um modelo ideal a ser alcançado nem propõe ajustar o paciente a um padrão de normalidade. A partir das concepções freudianas e lacanianas, Figueiredo (1997) propõe um norte ao psicanalista para levar a psicanálise à sua finalidade. Isso seria deslocar a dimensão alienante do "destino", entendido como "destino selado”, para a dimensão de uma separação, para um “destino aberto”. Dessa forma, o analista abre possibilidades para o que antes estava "selado", mas sabe que sempre resta algo que marca esse destino.

Figueiredo (1997) menciona o desejo do analista como última condição para identificar o trabalho analítico. As questões que norteiam a discussão da autora são: o que faz um analista tornar-se analista? Ou, o que quer um analista? Uma das recomendações deixadas por Freud (1937/1996) seria a própria análise do analista. Para ele, a condição necessária para se tornar analista é que o analisando deve obter a "convicção firme da existência do inconsciente para perceber em si mesmo coisas que de outra maneira seriam inacreditáveis" (FREUD, 1996, p.265). Portanto, Freud fala sobre a importância da experiência do inconsciente; não como algo místico, mas sim como a experiência do trabalho analítico em sua especificidade na produção de algo novo.

Segundo Figueiredo (1997), o que Lacan nomeia como desejo do analista é, em última instância, um efeito de análise. Dito de outra forma, o desejo do analista designa "o desejo que move alguém em análise - particularmente no período final de análise - a tornar-se analista. Esse mesmo desejo é o instrumento com o qual o analisante que se tornou analista vai operar, por sua vez, na condução do tratamento analítico de seus analisantes" (QUINET, 2003, p.110). Nesse ponto, pode-se retomar Figueiredo (1997) ao afirmar que “até onde se foi na própria análise determina a possibilidade e o limite de fazer operar o dispositivo que constitui o trabalho analítico a partir do desejo do analista" (FIGUEIREDO, 1997, p.163).

De acordo com Quinet (2003), o desejo do analista não se sustenta em nada: é um lugar vazio que ele oferece ao analisante, um espaço para que aí possa se instalar o desejo do analisante. Segundo as concepções lacanianas, o desejo do analista — como lugar vazio e operador de uma análise - possibilita, num processo analítico, que o retorno dos ditos que provocam a implicação do 
analisante em suas demandas circule e ponha em causa o que o movimentará enquanto sujeito do desejo.

Em relação às condições mínimas que caracterizam as especificidades da clínica psicanalítica, Figueiredo (1997) resume:

“Trata-se de uma clínica que diz respeito à realidade psíquica e, para isso, provoca um modo peculiar de fala que se dá a partir da transferência, numa relação também peculiar com o tempo, visando remanejar essa realidade por sucessivos deslocamentos. (...) E, last but not least, há a última condição, postulada por Lacan, que realiza as demais como operadores da clínica, a saber: o desejo do analista." (FIGUEIREDO, 1997, p.126)

\section{CONSIDERAÇÕES FINAIS: UMA PARTICULARIDADE DA CLÍNICA PSICANALÍTICA NO HOSPITAL GERAL}

Pensar a psicanálise fora do enquadre clássico não é tarefa fácil, pois, como se observou, Freud não teoriza sobre a inserção da psicanálise fora do enquadre convencional. Esse fato faz com que a clínica psicanalítica constantemente se misture a outros campos do saber. Dessa forma, a extensão da psicanálise exige do analista responsabilidade ética com sua formação e com a formalização da práxis analítica. Essas exigências são fundamentais para refletirmos sobre as condições de possibilidades para sustentar a psicanálise no hospital.

A partir das ideias discutidas ao longo deste artigo, apresentamos alguns desafios que o psicanalista enfrenta quando se insere em hospitais gerais. Esses desafios certamente nos convocam ao questionamento sobre a legitimidade da psicanálise nesses locais. Figueiredo (2007) expõe as condições mínimas para que se caracterizem as especificidades da clínica psicanalítica. Analisar esses dispositivos possibilitou-nos delimitar a clínica psicanalítica como determinada maneira de trabalho independentemente do lugar em que o psicanalista atue.

No caso dos hospitais, observa-se uma descaracterização e até mesmo uma alteração dos fundamentos da psicanálise por parte dos profissionais que se dizem psicanalistas. A partir do momento em que o psicanalista se insere num local marcado pelos critérios de eficácias e por um discurso que visa à restauração da saúde perdida, ele pode levar a psicanálise a se diluir nesses tratamentos que propõem o bem-estar. Então, refletir sobre as questões que envolvem as "condições mínimas” de um trabalho especificamente psicanalítico foi fundamental, já que, no contexto hospitalar, o analista é constantemente convocado a sustentar as especificidades da sua prática.

Para que o psicanalista possa praticar sua especificidade, ele precisa ter clareza de seus propósitos. No contexto hospitalar, o psicanalista com frequência sofre 
demandas provenientes de outros campos do saber e é importante que ele saiba disso, pois, às vezes, é preciso recuar. O analista deve acolher as demandas e encaminhamentos a ele dirigidos sem ceder às suas particularidades. Aqui se articulam as questões já suscitadas sobre as solicitações médicas. Ou seja, uma vez que o psicanalista tenha clareza dos seus dispositivos, é importante acolher as demandas médicas — independentemente das maneiras como são formuladas - e saber recuar quando necessário.

Esta posição não é alcançada apenas por meio dos livros e estudos didáticos, apesar de eles serem essenciais para a construção do saber referencial indispensável na formação. Entretanto, é a partir de sua trajetória de analisando a analista, em seu tempo próprio de elaboração, com avanços e recuos, que o analista pode convir com os pontos essenciais do trabalho psicanalítico no hospital geral.

Nessa direção, cita-se a conclusão de Moretto (2001): “O que um analista pode num hospital, concluo, não é mais nem menos do que ele pode em qualquer lugar. O que um analista pode fazer se aproxima bastante daquilo que ele deve fazer, daquilo que é sua função” (MORETTO, 2001, p.207). No entanto, para ocupar esse lugar, o analista precisa estar apto para isso; "ciente da sua função e dos seus limites, é bem provável que ele consiga fazer um trabalho rico e eficaz” (ibidem).

Assim, em última análise, concluímos que a aplicação da psicanálise para além dos consultórios privados é viável, mas depende fundamentalmente da implicação do psicanalista nas especificidades dessa clínica e na exigência de um rigor ético de formalização permanente de sua prática. Quando o analista tem clareza de seus propósitos e de sua função, é possível sustentar essa prática fora do enquadre clássico. Conforme Lacan (1953) afirma, a técnica não pode ser compreendida nem aplicada quando se desconhecem os conceitos que a fundamentam. "Nossa tarefa será demonstrar que esses conceitos só adquirem pleno sentido ao se orientarem num campo de linguagem, ao se ordenarem na função da fala” (LACAN, 1998, p.247).

Diante das questões levantadas, podemos introduzir e refletir acerca das condições mínimas para o trabalho analítico no hospital. Vimos que Figueiredo (1997) empregou esse termo para caracterizar as especificidades da clínica psicanalítica, independentemente do contexto onde o psicanalista se insere. No entanto, neste momento, a proposta é utilizarmos o termo "condição mínima” para pensarmos o trabalho analítico num contexto específico, que é o hospital geral. Conforme veremos adiante, essa condição pode ser localizada como uma das particularidades do trabalho analítico no hospital. O que seriam essas particularidades?

A partir das discussões aqui levantadas, podemos concluir que a função do analista nos hospitais é a mesma que ele exerce no consultório particular. No 
entanto, no contexto hospitalar, ele é obrigado a lidar com muitas variáveis que não se apresentam no seu trabalho no consultório. Designamos essas variáveis como 'particularidades'.

O psicanalista no hospital se afasta das normas e padrões adotados pelas técnicas convencionais. Ele encontra à sua disposição um conjunto limitado de utensílios e materiais. Além da ausência do tradicional divã, muitas vezes faltam salas para o atendimento ou, embora elas existam, os atendimentos podem também ocorrer nos corredores ou escadarias do hospital.

Em função dessas variedades, o psicanalista no hospital constantemente se depara com situações imprevisíveis, mas que, ao mesmo tempo, convocam seu trabalho. Assim, as possibilidades de produzir as condições mínimas para que se estabeleça um trabalho analítico são diversas. Portanto, para que esse trabalho seja possível, é preciso contar com a criatividade do analista; com a capacidade de produzir recursos simbólicos para a instauração dos dispositivos analíticos, visto que tais recursos são precários no hospital. Dito de outra forma, diante das surpresas provocadas pelas situações do cotidiano hospitalar, é imprescindível o saber fazer do analista no que concerne às condições para que a prática do trabalho analítico seja possível.

Por exemplo, pode acontecer de o analista estar atendendo um paciente e um médico chegar para examiná-lo. Dependendo da gravidade do caso, às vezes, é preciso que o analista interrompa o atendimento justamente num momento importante do processo analítico. Pode acontecer também que o analista esteja atendendo um familiar no momento em que o paciente falece, ali, na sua frente. Ou ainda, que o psicanalista seja abordado, nas escadarias do hospital, pela equipe da enfermagem para atender um familiar que está "aos berros" no corredor, pois o paciente acabou de sofrer uma parada cardíaca e o familiar precisou sair do quarto para que ele fosse atendido. Recorremos também às diversas situações dos familiares no CTI em que muitas vezes o psicanalista precisa se aproximar — ou até criar situações para isso ocorrer - e oferecer sua escuta, pois dali pode surgir uma demanda. Mencionamos ainda aquelas situações em que o paciente é atendido em enfermarias com várias pessoas internadas no mesmo local e que começam a ouvir — e até oferecem conselhos e opiniões o atendimento dele.

Poderíamos citar vários outros exemplos que fazem parte do cotidiano da prática do psicanalista no hospital, entretanto uma questão permeia essas situações: o que o analista pode fazer diante desses casos inusitados, mas que são frequentes no seu cotidiano hospitalar — os elementos singulares de cada situação implicam uma configuração irredutível e não podem ser desconsiderados - e que inicialmente parecem impedir seu trabalho? 
Nesse ponto, introduziremos a ideia de que uma condição mínima para que o trabalho do psicanalista no hospital seja viável é sua capacidade de inventar meios de oferecer condições para a instalação dos dispositivos psicanalíticos. A partir da prática no hospital, percebe-se que diante de tantas situações imprevisíveis, de urgência e de crise — acontecimentos que muitas vezes provocam grande sofrimento - é essencial que o psicanalista crie condições simbólicas para a prática da psicanálise. Portanto, tem-se aí a ideia de que o que legitima o trabalho analítico no hospital é o próprio psicanalista, que deve sustentar a existência do inconsciente a partir dos próprios dispositivos psicanalíticos. Para cada analista, trata-se de reinventar os meios para a instalação desses dispositivos, no particular de cada caso.

É possível localizarmos essa capacidade do psicanalista descrita anteriormente como uma particularidade do trabalho analítico no hospital. De fato, essa ideia implica abertura para pensarmos em outras particularidades da clínica psicanalítica nesses espaços. Entretanto, investigar e analisar essas condições particulares são questões para outros estudos.

Recebido em 9/8/2010. Aprovado em 10/11/2010.

\section{REFERÊNCIAS}

FIGUEIREDO, A. (1997) Vastas confusões e atendimentos imperfeitos. Rio de Janeiro: Relume-Dumará.

FREUD, S. (1996) Edição standard brasileira das obras psicológicas completas de Sigmund Freud. Rio de Janeiro: Imago.

(1896) "Observações adicionais sobre as neuropsicoses de defesa", v.III, p.159-183.

(1900) "O inconsciente e a consciência — realidade", in A interpretação dos sonhos, v.V, p.635-645.

(1912a) "Recomendações aos médicos que exercem a psicanálise", v.XII, p.123-133.

(1912b) “A dinâmica da transferência”, v.XII, p.109-119.

(1913) "Sobre o início do tratamento (Novas recomendações sobre a técnica da psicanálise I)”, v.XII, p.137-158.

(1914) "Recordar, repetir e elaborar (Novas recomendações sobre a técnica da psicanálise II)”, v.XII, p.161-171.

(1915) “O inconsciente”, v.XIV, p.165-209.

(1917) "Os caminhos da formação dos sintomas”, v.XVI, p.361-378.

(1919 [1918a]) “Linhas de progresso na terapia psicanalítica”, v.XVII, p.173-181.

(1919 [1918b]) “Sobre o ensino da psicanálise nas universidades", v.XVII, p.185-189. 
(1925[1924]) “Um estudo autobiográfico", v.XX, p.15-72.

(1926 [1925]) “Psicanálise”, v.XX, p.251-259.

(1933[1932]) “Conferência XXXIV: Explicações, aplicações e orientações”, v.XXII, p.135-154.

(1937) “Análise terminável e interminável”, v.XXIII, p.225-270.

LACAN, J. (1953/1998) "Função e campo da fala e da linguagem em psicanálise”, in Escritos. Rio de Janeiro: Jorge Zahar.

(1958/1998) "A direção do tratamento e os princípios do seu poder”, in Escritos. Rio de Janeiro: Jorge Zahar.

(1967/2003) "Proposição de 9 de outubro de 1967 sobre o psicanalista da Escola”, in Outros escritos. Rio de Janeiro: Jorge Zahar.

MEZAN, R. (1998) “O psicanalista como sujeito moral”, in Tempo de muda: ensaios de psicanálise. São Paulo: Companhia das Letras.

MORETTO, M.L.T. (2001) O que pode um analista no hospital? São Paulo: Casa do Psicólogo.

QUINET, A. (2003) "Demanda e desejo", in A descoberta do inconsciente: do desejo ao sintoma. Rio de Janeiro: Jorge Zahar.

ROUDINESCO, E. \& PLON, M. (1998) Dicionário de psicanálise. Rio de Janeiro: Jorge Zahar.

Maíla Do Val Machado

mailamachado@yahoo.com.br

Daniela Sheinkman Chatelard

dchatelard@gmail.com 